\title{
Transanal Tube as a Means of Prevention of Anastomotic Leakage after Rectal Cancer Surgery
}

\author{
Zuzana Adamova \\ Department of Surgery, Vsetin Hospital, Vsetin, Czech Republic
}

\section{Keywords}

Rectal cancer - Low anterior resection .

Anastomotic leakage - Transanal tube

\section{Summary}

Background: Anastomotic leaks after low anterior resection for rectal cancer remain the most feared complication. The aim of our study was to investigate whether the use of a transanal tube could reduce the leakage rate after this surgical procedure. Methods: This is a retrospective analysis of a single-institution experience. The study includes 66 patients who underwent low anterior resection for rectal cancer without stoma creation between January 2008 and June 2013. Patients were divided into two groups, i.e. those with a transanal drainage tube (TT; $n=9$ ) and those without tube (NTT; $n=57$ ), and evaluated for clinically evident anastomotic leakage and postoperative complications. Results: The postoperative anastomotic leakage appeared in 5 patients $(9 \%)$ in the NTT group while no single case was observed within the TT group. Despite the disadvantageous background in the TT group (a transanal stent was used in the most high-risk patients), these patients had no postoperative complications. In the NTT group, $23 \%$ had some kind of postoperative complications, and $5 \%$ died. The difference between the two groups is not significant. Conclusions: Our study showed that the use of a transanal tube in low anterior resection for rectal cancer could potentially be a simple and effective method of reducing anastomotic leakage. In order to prove our observations, larger prospective randomized studies should be performed.

\author{
Schlüsselwörter \\ Rektumkarzinom - Tiefe anteriore Resektion . \\ Anastomoseninsuffizienz · Transanales Darmrohr
}

\section{Zusammenfassung}

Hintergrund: Anastomoseninsuffizienzen bleiben die am meisten gefürchtete Komplikation nach tiefer anteriorer Resektion bei Rektumkarzinom. Das Ziel unserer Studie bestand darin, zu untersuchen, ob die Verwendung eines transanalen Darmrohrs die Leckagerate nach diesem chirurgischen Eingriff reduzieren könnte. Methoden: Es handelt sich hierbei um die retrospektive Analyse einer Single-Center-Erfahrung. Die Studie umfasst 66 Patienten, die sich zwischen Januar 2008 und Juni 2013 einer tiefen anterioren Resektion bei Rektumkarzinom ohne Schaffung eines Stomas unterzogen. Die Patienten wurden in zwei Gruppen, d.h. solche mit einem transanalen Darmrohr (TT; $n=9$ ) und solche ohne Darmrohr (NTT; $n=57$ ), unterteilt und bezüglich klinisch evidenter Anastomoseninsuffizienzen sowie postoperativer Komplikationen ausgewertet. Ergebnisse: Die postoperative Anastomoseninsuffizienz trat bei 5 Patienten (9\%) in der NTT-Gruppe auf, während kein einziger Fall in der TT-Gruppe beobachtet wurde. Trotz des mit Nachteilen behafteten Hintergrunds der TT-Gruppe (ein transanaler Stent wurde bei denjenigen Patienten mit dem allerhöchsten Risiko verwendet) hatten diese Patienten keine postoperativen Komplikationen. In der NTTGruppe trat bei $23 \%$ eine Art von postoperativer Komplikation auf, und 5\% der Patienten verstarben. Der Unterschied zwischen den beiden Gruppen ist nicht signifikant. Schlussfolgerungen: Unsere Studie belegte, dass die Verwendung eines transanalen Darmrohrs bei tiefer anteriorer Resektion bei Rektumkarzinom möglicherweise eine einfache und effektive Methode zur Reduktion von Anastomoseninsuffizienzen sein könnte. Um unsere Beobachtungen zu bestätigen, sollten größere prospektiv randomisierte Studien durchgeführt werden.

\section{KARGER \\ Fax +497614520714

Zuzana Adamova, MD 


\section{Introduction}

In recent years, there has been a rapid development in the surgery for rectal cancer. Low anterior resection is more commonly performed for the treatment of middle and lower rectal cancer. Abdominoperineal resection, the previous gold standard in the treatment of rectal cancer, has been regarded as unnecessary in most patients, and more patients can now be treated with sphincter-saving surgery. Total mesorectal excision (TME) has been accepted as the standard method for rectal surgery because it reduces the local recurrence rate, increases the survival rate, and shows better functional results. After laparoscopic surgery was adopted, it has been showing promising results. However, neither laparoscopic nor open surgery is completely safe from the risk of anastomotic leakage.

Actually, anastomotic leakage continues to be the most frustrating and feared complication of colorectal surgery, leading to significant morbidity, fistulas, peritonitis and sepsis, increased mortality, and prolonged hospital stay [1]. It may also affect the patients' postoperative quality of life and causes substantial extra cost. Conversely, there could be an increased risk of anastomotic dehiscence associated with TME as it potentially endangers the blood supply of the rectal stump [2]. Anastomotic leakage is reported at a rate of $2-20 \%$ and is usually higher than $10 \%$ [3-11]. A low level of anastomosis and male gender is usually regarded as the significant factor that increases the rate of anastomotic leakage [12]. The postoperative mortality associated with anastomotic complications varies between 6 and 22\% [12]. Therefore, the creation of a diverting stoma for proximal fecal diversion has been suggested for patients undergoing low anterior resection. A stoma itself, however, has clinical disadvantages such as patient discomfort, the need for stoma closure surgery, and cost of stoma care aids. A study performed in Austria [13] showed the overall stoma closure-related mortality rate at $3 \%$ and a rate of stoma closure-related surgical complications of $20 \%$. From the economic point of view, defunctioning stomas have a major effect on the overall cost of treatment [14].

Therefore, we investigated the usage of transanal tubes in patients who were at a high risk for postoperative anastomotic leakage. Only few studies on the safety or efficacy of such transanal tubes exist [15-18]. The aim of our study was to retrospectively assess the difference in the rate of symptomatic leakage and prove the efficacy of transanal tubes in patients after low anterior resection of the rectum.

\section{Patients and Methods}

\section{Patients}

This is a single-center, retrospective study. It includes the patients who underwent elective low anterior resection (laparoscopy-assisted or open) for rectal cancer between January 2008 and June 2013. Patients with abdominoperineal resection, partial and total pelvic exenteration, and those who underwent a protective defunctioning stoma procedure were excluded. Rectal cancer was confirmed preoperatively by colonoscopy and biopsy. The tumor located within $10 \mathrm{~cm}$ of the anal verge was the primary criterion. A total of 66 patients met these criteria.

Patients were divided into two groups, i.e. those with a transanal drainage tube (TT) and those without tube (nontransanal drainage tube (NTT)). Because of the price of NO COIL ${ }^{\circledR}$ (silicone tube; Sapi Med S.p.A., Alessandria, Italy), we used this transanal drainage only in patients with the highest risk of anastomotic leakage. The average ASA (American Society of Anesthesiologists) status of this group was 3, and the average distant margin of the tumor was $5 \mathrm{~cm}$ above the anal verge. Each patient of this group had either diabetes mellitus or atherosclerosis. They were also treated for hypertension $(8 \times)$, Parkinson's disease $(1 \times)$, hepatopathy $(2 \times)$, coagulation disorders $(2 x)$, etc. Two of them received neoadjuvant radiotherapy.

\section{Surgical Procedure}

According to the fast-track protocol, our patients do not receive any oral mechanical bowel preparation. Cefuroxime (Axetine ${ }^{\circledR}$ ) is given 30 min prior to the incision. A repeated dose of a prophylactic antibiotic is administered during operations lasting more than $2 \mathrm{~h}$ and then stopped within $24 \mathrm{~h}$ after the operation. The procedure is conducted in the lithotomy position and starts either with a midline incision or with the placement of four ports. Once the medial white line of Toldt of the sigmoid colon is identified, the incision is performed. The sigmoid colon is then mobilized by the medial-to-lateral approach in Toldt's space. The inferior mesenteric artery is dissected (below the origin of the left colic artery, i.e. low tie). The inferior mesenteric vein is cut at the same level. The preparation of the sigmoid is completed and then the procedure is continued down to the pelvis along the anatomic space between the visceral and parietal endopelvic fascia. Ultrasonic devices are used for preparation. If necessary, the descending colon and splenic flexure are mobilized. The rectum is transected transversely using a stapler, ideally $2 \mathrm{~cm}$ distal to the inferior margin of the tumor. In the case of a laparoscopic approach, we perform a short midline incision to extract the specimen. The proximal colon is transected at a level of about $10-15 \mathrm{~cm}$ proximal to the upper edge of the tumor. An end-to-end colorectal or coloanal stapler anastomosis is performed. Anastomotic air tightness is tested by instillation of air. A drain is always placed beside the anastomosis. With high-risk patients, the drainage tube (NO COIL) is gently inserted into the anus and fixated with a skin suture after the suture of abdominal wall incisions. In most cases, the tube is removed 5-6 days after surgery.

\section{Definitions of Anastomotic Leakage}

The suspicion was based on clinical symptoms, i.e. abdominal pain, abdominal distension, leukocytosis, CRP elevation, fever; emission of gas, pus, or feces via the drains, the laparotomy incision, or the vagina; peritonitis. We confirmed the suspicion of anastomotic leakage by computed tomography (CT). If the clinical examination was unambiguous, we verified an anastomotic leakage directly during relaparotomy.

\section{Statistical Analysis}

The data were evaluated using descriptive statistical methods. Statistical analyses were performed using the statistical software Six Sigma, version 7. Pearson's chi-squared test was used for categorical variables. Continuous variables were compared using the Mann-Whitney U test. A value of $\mathrm{p}<0.05$ was considered statistically significant.

\section{Results}

In our study, 69 patients underwent anterior resection for low rectal cancer. Defunctioning stoma was indicated in 3 of 
Table 1. Comparison of the TT and NTT groups

\begin{tabular}{llll}
\hline & $\begin{array}{l}\text { TT group } \\
(\mathrm{n}=9)\end{array}$ & $\begin{array}{l}\text { NTT group } \\
(\mathrm{n}=57)\end{array}$ & p value \\
\hline Mean age, years & 65 & 64 & 0.6 \\
Gender (female:male ratio) & $3 / 6$ & $28 / 29$ & 0.4 \\
Anastomic leak & 0 & $5(9 \%)$ & 0.4 \\
Complications & 0 & $13(23 \%)$ & 0.1 \\
Death & 0 & $3(5 \%)$ & 0.5 \\
\hline
\end{tabular}

them, and those patients were excluded from the study. The characteristics of the remaining 66 patients are presented in table 1. Age and sex did not differ significantly between the two groups.

The rate of postoperative anastomotic leakage was $9 \%$ in the NTT group and $0 \%$ in the TT group. The difference between the NTT and the TT group was found not to be statistically significant. All 5 patients with anastomotic dehiscence underwent surgery, and a diverting stoma was created in 4 cases. In 1 patient, the transanal tube was placed in the rectum and an abdominal drain was fixed to the anastomosis. One of these patients died ( 32 days after the operation from ischemic stroke). 2 other patients from the NTT group died from metabolic decompensation and pulmonary embolism. Another 10 patients from the NTT group had complications (cardiac decompensation $2 \times$, atrial fibrillation $1 \times$, pneumonia $2 \times$, surgical site infections $5 \times$, disorientation $1 \times$, urinary tract infection $1 \times)$. No complications were observed in the TT group. This result, however, cannot be considered as statistically significant due to the limited number of patients in the TT group.

\section{Discussion}

The introduction of TME surgery as a surgical technique of choice for rectal carcinoma has led to a decreased local recurrence of rectal carcinoma and to an improved oncologic outcome. Nevertheless, postoperative morbidity and early mortality after anterior resection of the rectum remain important issues, with symptomatic anastomotic leakage being the most feared complication.

The most important risk factor for leakage is the low anastomosis. Vignali et al. [19], for example, reported that anastomotic dehiscence occurred in $8 \%$ after stapling within $7 \mathrm{~cm}$ from the anal verge and in $1 \%$ after stapling higher than $7 \mathrm{~cm}$ $(\mathrm{p}<0.001)$. Similar results were described by Pakkastie et al. [20] who also identified the divide between high and low anastomosis at $7 \mathrm{~cm}$ above the anal verge. The high leakage rate associated with low anastomosis is probably due to a combination of anatomical inaccessibility, suboptimal blood supply, tightly closed anal sphincter below a low anastomosis, and an infected hematoma that may discharge through the anastomo- sis. There are also other contributing factors such as male gender, preoperative steroid use, comorbidities, malnutrition, longer duration of the operation, contamination of the operative field, and preoperative radiation [1-3]. Some studies demonstrated a reduction in leakage rates in patients with diverting stoma; however, other studies revealed that the creation of an ileotransversostomy had no effect on leakage rates although it reduced the severity of consequences of an anastomotic leakage. In contrast, a defunctioning stoma means the risk of another operation, the probability of a permanent stoma (20-25\%) [21, 22], a higher cost, and a lower quality of life. This is the reason why a few studies focus on the defunctioning transanal catheter which could play a role in decompression and drainage on the proximal side of the anastomosis and should decrease the incidence of leakage.

In our study, anastomotic leakage occurred in a total of 5 patients $(7.6 \%)$, whereas none of the leaks occurred in the TT group. Despite the disadvantageous background in the TT group (a transanal stent was used by a surgeon in the most high-risk patients), these patients had no postoperative complications, and nobody died. Although not statistically significant, our results demonstrate that the use of a transanal tube contributed to a decrease in anastomotic leakage, in overall complications, and in the mortality rate after low rectal surgery. In the early postoperative period, the anal sphincter is under tight contraction and spasm due to factors such as pain, fear, inflammation, and trauma. The action mechanism of the transanal tube may result from a reduction in intraluminal pressure, reducing the risk of fecal extrusion through the staple line.

In Great Britain, where 76 patients were randomized into two groups, no difference was reported in the leakage rate (7\% in the stoma group compared with $6 \%$ in the transanal stent group). The transanal stent was made of a radio-opaque soft silicone tube, $4 \mathrm{~cm}$ in length with funnel-shaped flanges [17]. General infectious complications were less frequent in the transanal stent group (17 vs. $35 \%$ ). In a Chinese study, the group with a transanal tube had significantly fewer anastomotic complications compared to the group without this tube ( 2.5 vs. $11.7 \% ; p=0.029$ ) [15]. In this study, 81 patients were included in the group with tube and 77 patients in the group without tube. The transanal catheter was made of an ordinary rubber drainage tube and had a relatively large diameter (26 French) [15].

An older but larger Chinese study dealing with risk factors of an anastomotic leak considered the transanal tube as a risk factor. In this series, 278 patients underwent defunctioning stoma or defunctioning transanal catheter placement, whereas 15 of them had the two procedures at the same time. In the remaining 244 patients, no protective measures were taken. The leakage rate of the transanal catheter placement group was significantly higher than that of the noncatheter group (15.1 vs. $4.9 \% ; \mathrm{p}=0.008)$. The authors do not mention the type of catheter, while the study is large but retrospective and the groups are not clearly defined [3]. 
Table 2. Studies on transanal tubes aimed at preventing anastomotic leakage

\begin{tabular}{|c|c|c|c|c|c|c|c|}
\hline \multirow[t]{2}{*}{ Study [Ref] } & \multirow[t]{2}{*}{ Year } & \multirow[t]{2}{*}{ TT group } & \multirow[t]{2}{*}{ Controls } & \multirow[t]{2}{*}{ Type of study } & \multicolumn{2}{|c|}{ Anastomotic leak, \% } & \multirow[t]{2}{*}{$\mathrm{p}$ value } \\
\hline & & & & & TT group & controls & \\
\hline Amin et al. [17] & 2003 & 41 (- stoma) & 35 (+ stoma) & $\begin{array}{l}\text { prospective } \\
\text { randomized }\end{array}$ & 6 & 7 & ns \\
\hline Zhao et al. [15] & 2013 & 81 (- stoma) & 77 (- stoma) & $\begin{array}{l}\text { prospective } \\
\text { nonrandomized }\end{array}$ & 3 & 8 & ns \\
\hline Cong et al. [3] & 2009 & $62( \pm$ stoma $)$ & $676( \pm$ stoma $)$ & retrospective & 15 & 4 & 0,000 \\
\hline Xiao et al. [16] & 2011 & 200 (- stoma) & 198 (- stoma) & $\begin{array}{l}\text { prospective } \\
\text { randomized }\end{array}$ & 4 & 10 & 0.026 \\
\hline Nishigori et al. [4] & 2014 & 36 (- stoma) & 140 (- stoma) & retrospective & 3 & 16 & 0.04 \\
\hline Bülow et al. [23] & 2006 & 98 ( \pm stoma $)$ & 96 ( \pm stoma $)$ & $\begin{array}{l}\text { prospective } \\
\text { randomized }\end{array}$ & 17 & 8 & ns \\
\hline Sterk et al. [24] & 2001 & 50 (- stoma) & & & 4 & & \\
\hline Montemurro et al. [25] & 2012 & 184 (- stoma) & & & 5 & & \\
\hline
\end{tabular}

The third study of the same Chinese origin is more optimistic. The authors randomized 398 patients into groups with and without transanal stent. Patients with a transanal tube (200 patients) had leakage in $4.0 \%$ and those without a tube (198 patients $)$ in $9.6 \%(p=0.026)$. A shorter length of hospital stay was also associated with the use of a transanal tube [16].

A Japanese publication claims that the placement of a transanal tube is effective in decreasing the rate of anastomotic leakage. Patients who received a transanal tube (36 patients) had a lower risk of anastomotic leakage compared to the control group, which did not receive a transanal tube or diverting stoma (140 patients; 1 (2.7\%) vs. 22 (16\%); p = 0.04). They used a 24 French Ficon tube (Fuji Systems, Tokyo, Japan) which was inserted per anus, and the tip was placed approximately $3-5 \mathrm{~cm}$ from the oral side of the anastomosis [4].

A randomized multicenter trial with 194 patients was carried out in Denmark. The surgeon decided to use protective ileostomy, and after completion of the operation the patients were randomized into two groups, i.e. with and without a transanal tube (transanal silicone stent [17]). The analysis showed no significant protective effect of the catheter on forming localized erosion of the rectal wall or anastomosis. The localized erosion resulted in ischemia and perforation [23].

In Germany, Sterk et al. [24] used a 40-cm long transanal rubber drain in 50 patients. $10 \%$ of the patients developed an anastomotic leakage, $4 \%$ with a clinically evident anastomotic leakage and $6 \%$ with an asymptomatic anastomotic leakage detected by CT. The authors consider the transanal drain as at least equivalent to a conventional colostomy in terms of reducing symptomatic anastomotic leakage [24].
An Italian study that used the same transanal tube as we did in our study (NO COIL) considers this catheter as an alternative option to diverting stoma. First, with a transanal tube, they measured the intraluminal rectal pressure which was strongly reduced from 14 to $5 \mathrm{~mm} \mathrm{Hg}(\mathrm{p}<0.01)$. Then they performed surgery on 184 patients with just the transanal stent, i.e. no stoma was created. The leakage rate reported by the authors was $4.8 \%$. They did not have any control group [25].

Publications concerning this topic are summarized in table 2 .

\section{Conclusions}

We are well aware of the fact that our groups are small and that the results are not statistically significant. Nevertheless, they are quite optimistic, demonstrating that the use of a transanal tube could contribute to the decreasing rate of anastomotic leakage after low rectal surgery, especially when the transanal tube is used in the most high-risk patients. Based on a search of the literature, although there is currently not much high-level evidence, we believe that the use of the transanal tube in anterior resection for rectal cancer could be a simple and effective method of reducing the occurrence of anastomotic leakage. Larger randomized prospective studies should be performed in the future.

\section{Disclosure Statement}

No conflict of interest. 


\section{References}

1 Ruggiero R, Sparavigna L, Docimo G, et al: Postoperative peritonitis due to anastomotic dehiscence after colonic resection. Multicentric experience, retrospective analysis of risk factors and review of the literature. Ital Chir 2011;82:369-375.

2 Carlsen E, Schlichting E, Guldvog I, Johnson E, Heald RJ: Effect of the introduction of total mesorectal excision for the treatment of rectal cancer. Br J Surg 1998;85:526-529.

> Cong ZJ, Fu CG, Wang HT, Liu LJ, Zhang W, Wang H: Influencing factors of symptomatic anastomotic leakage after anterior resection of the rectum for cancer. World J Surg 2009;33:1292-1297.

4 Nishigori H, Ito M, Nishizawa Y, Nishizawa Y, Kobayashi A, Sugito M, Saito N: Effectiveness of a transanal tube for the prevention of anastomotic leakage after rectal cancer surgery. World J Surg 2014;38:1843-1851.

5 Konishi T, Watanabe T, Kishimoto J, Nagawa H Risk factors for anastomotic leakage after surgery for colorectal cancer: results of prospective surveillance. J Am Coll Surg 2006;202:439-444.

$\checkmark 6$ Law WL, Chu KW: Anterior resection for rectal cancer with mesorectal excision: a prospective evaluation of 622 patients. Ann Surg 2004;240:260-268.

7 Matthiessen P, Hallböök O, Andersson M, Rutegård J, Sjödahl R: Risk factors for anastomotic leakage after anterior resection of the rectum. Colorectal Dis 2004;6:462-469.

8 Machado M, Hallböök O, Goldman S, Nyström PO, Järhult J, Sjödahl R: Defunctioning stoma in low anterior resection with colonic pouch for rectal cancer a comparison between two hospitals with a different policy. Dis Colon Rectum 2002;45:940-945.
Skrovina M, Soumarova R, Kycina R, et al: Anastomotic leakage after laparoscopic total mesorectal excision for low rectal cancer. Videosurgery Miniinv 2011;6:5-11.

10 Hut'an M, Lukác I, Poticný V: Prevention of the anastomosis dehiscence following low anterior rectal resections (article in Slovakian). Rozhl Chir 2005;84:501-504.

11 Fontanili M, Caforio M, Asteria C: Perioperative complications in traditional surgery of the rectum. Minerva Chir 1997;52:217-224.

12 Rullier E, Laurent C, Garrelon JL, Michel P, Saric J, Parneix M: Risk factors for anastomotic leakage after resection of rectal cancer. Br J Surg 1998;85: 355-358.

13 Pokorny H, Herkner H, Jakesz R, Herbst F: Mortality and complications after stoma closure. Arch Surg 2005;140:956-960.

14 Koperna T: Cost-effectiveness of defunctioning stomas in low anterior resections for rectal cancer: a call for benchmarking. Arch Surg 2003;138:1334-1338.

15 Zhao WT, Hu FL, Li YY, Li HJ, Luo WM, Sun F: Use of a transanal drainage tube for prevention of anastomotic leakage and bleeding after anterior resection for rectal cancer. World J Surg 2013;37:227-232.

16 Xiao L, Zhang WB, Jiang PC, Bu XF, Yan Q, Li H et al.: Can transanal tube placement after anterior resection for rectal carcinoma reduce anastomotic leakage rate? A single-institution prospective randomized study. World J Surg 2011;35:1367-1377.

17 Amin AI, Ramalingam T, Sexton R, Heald RJ, Leppington-Clarke A, Moran BJ: Comparison of transanal stent with defunctioning stoma in low anterior resection for rectal cancer. Br J Surg 2003;90: $581-582$.
8 Pătraşcu T, Doran H, Muşat O: Protective transanal tube in colo-rectal anastomosis (article in Hungarian). Chirurgia (Bucur) 2004;99:75-78.

19 Vignali A, Fazio VW, Lavery IC, et al: Factors associated with the occurrence of leaks in stapled rectal anastomoses: a review of 1,014 patients. J Am Coll Surg 1997;185:105-113.

20 Pakkastie TE, Luukkonen PE, Järvinen HJ: Anastomotic leakage after anterior resection of the rectum. Eur J Surg 1994;160:293-297.

21 David GG, Slavin JP, Willmott S, Corless DJ, Khan AU, Selvasekar CR: Loop ileostomy following anterior resection: is it really temporary? Colorectal Dis 2010;12:428-432.

-22 Lindgren R, Hallböök O, Rutegård J, Sjödahl R, Matthiessen P: What is the risk for a permanent stoma after low anterior resection of the rectum for cancer? A six-year follow-up of a multicenter trial. Dis Colon Rectum 2011;54:41-47.

23 Bülow S, Bulut O, Christensen IJ, Harling H: Transanal stent in anterior resection does not prevent anastomotic leakage. Colorectal Dis 2006; 8 : 494-496.

24 Sterk P, Schubert F, Günter S, Klein P: Anastomotic protection with a transanal tube after rectum resection and total mesorectal excision. Zentralbl Chir 2001;126:601-604.

25 Montemurro S, De Luca R, Caliandro C, et al: Transanal tube NO COIL ${ }^{\circledR}$ after rectal cancer proctectomy. The 'G. Paolo II' Cancer Centre experience. Tumori 2012;98:607-614. 